\title{
Health consequences of reduced daily cigarette consumption
}

\section{Aage Tverdal, Kjell Bjartveit}

See end of article for authors' affiliations

.........................

Correspondence to: K Bjartveit, Fridtjof Nansens vei $24 \mathrm{~B}, \mathrm{~N}-0369$ Oslo, Norway; kjell. bjartveit@chello.no

Received 14 February 2006 Accepted 16 August 2006

\begin{abstract}
Objective: To determine the risk of dying from specified smoking-related diseases and from any cause in heavy smoking men and women ( $\geqslant 15$ cigarettes/day), who reduced their daily cigarette consumption by $>50 \%$.

Design: A prospective cohort study.

Setting: Three counties in Norway.

Participants: 24959 men and 26251 women, aged 20-49 years, screened for risk factors of cardiova?scular disease in the mid-1970s, screened again after 3-13 years, and followed up throughout 2003.

Outcomes: Absolute mortality and relative risks adjusted for confounding variables, of dying from all causes, cardiovascular disease, ischaemic heart disease, all smoking-related cancer and lung cancer.

Results: With sustained heavy smokers as reference, the smokers of both sexes who reduced their daily consumption (reducers) had the following adjusted relative risks (95\% confidence interval (CI)): of dying from any cause, 1.02 (0.84 to 1.22); cardiovascular disease, 1.02 (0.75 to 1.39); ischaemic heart disease, 0.96 (0.65 to 1.41); smoking-related cancer, 0.86 (0.57 to 1.29); and lung cancer, 0.66 (0.36 to 1.21). The difference in cigarette consumption between two examinations was not a significant predictor of death from any of the causes. A follow-up from a third screening of the subgroup who were reducers at both second and third examinations (sustained reducers) did not have a lower risk than those who were heavy smokers at all three examinations.

Conclusions: Long-term follow-up provides no evidence that heavy smokers who cut down their daily cigarette consumption by $>50 \%$ reduce their risk of premature death significantly. In health education and patient counselling, it may give people false expectations to advise that reduction in consumption is associated with reduction in harm.
\end{abstract}

D oes reduced daily cigarette consumption lead to lower mortality from the serious health consequences of cigarette smoking? In other words, does a reduction in consumption bring about reduction in harm?

Numerous population studies have given ample evidence that quitting smoking entirely results in a marked reduction in the ill effects of smoking. Up to now, however, only one large prospective study has explored the long-term effects of unassisted reduced smoking. Godtfredsen et $a l^{1-4}$ have pioneered in this field by following up a population of nearly 20000 men and women living in Copenhagen, Denmark (the Copenhagen Centre for Prospective Population Studies). After mean observation periods ranging from 13.8 to 18 years, they published their results in a series of articles.

The aim of this paper is to determine the risk in heavy smokers who reduced their cigarette consumption by at least $50 \%$, named "reducers", compared with those who continued as heavy smokers. We report on a Norwegian population of 51210 men and women, aged 20-49 years, who were examined in the mid1970s for cardiovascular disease risk factors and were examined again during the next 3-13 years at least once. These people were followed up throughout 2003 for deaths from serious smoking-related diseases and from all causes. The mean observation period is 21.2 years, maximum 27 years. A subgroup attended three screenings. This gave us the possibility to compare those who were reducers at the two last screenings ( sustained reducers) with those who were heavy smokers at all three screenings (sustained heavy smokers).

\section{METHODS} Initial screening

Between 1974 and 1978, screening examinations for cardiovascular disease were undertaken in three Norwegian counties with a mainly rural settlement (Finnmark, Sogn og Fjordane, and Oppland). All male and female residents aged 35-49 years were invited, and so was a $10 \%$ random sample of residents aged 20-34 years. The attendance was $88 \%{ }^{5}$

An identical protocol was applied for the screening programme in the three counties concerned. It included a questionnaire related to well-known risk factors of cardiovascular disease. Height, weight and blood pressure were measured, and a non-fasting blood sample was drawn and serum analysed at the same laboratory for total cholesterol, triglycerides and glucose. Details on results from the first screening have been published previously. ${ }^{6}$

A more extensive report on this study population after 13 years of observation with relevance to smoking and mortality has been published previously, ${ }^{7}$ and also another report compiled after 25 years of observation, concentrating on the risk in people smoking 1-4 cigarettes. ${ }^{8}$

\section{Second and third screenings}

In one county, Finnmark, two new screenings were conducted after 3 and 13 years. In the other two counties (75\% of the total study population), the re-screenings were carried out around 5 and 10 years after the initial screening. ${ }^{9-11}$

At the second screening, all those invited to the initial screening were re-invited and, in addition, a 9\% random sample of people aged 20-34 years who were not invited to the first examination. The attendance was $88 \% .{ }^{12}$

At the third screening, minor modifications were made in the eligibility to the examinations; the main core of participants in the previous rounds, however, was re-invited. Owing to capacity constraints, only a $10 \%$ random sample of the cohort aged 45-49 years at the first screening was invited. The attendance rate was $84 \% .^{10}{ }^{13} 14$ 
Table 1 Background characteristics at the last examination of participants*, by category of smoking

\begin{tabular}{|c|c|c|c|c|c|c|c|}
\hline & $\begin{array}{l}\text { Never } \\
\text { smokers }\end{array}$ & Ex-smokers & Quitters & $\begin{array}{l}\text { Moderate } \\
\text { smokers }\end{array}$ & Reducers & $\begin{array}{l}\text { Heavy } \\
\text { smokers }\end{array}$ & p Valuet \\
\hline \multicolumn{8}{|l|}{ Men $(n=23$ 978) } \\
\hline Age (years) & $40.6(7.1)$ & $42.9(5.9)$ & $41.5(6.9)$ & $41.4(7.3)$ & $41.5(7.4)$ & $41.7(6.9)$ & 0.576 \\
\hline Cigarette consumption (no/day) & - & $13.7(8.4)$ & $14.7(8.4)$ & $10.6(4.6)$ & $9.7(4.1)$ & $18.3(6.6)$ & $<0.001$ \\
\hline Duration of smoking (years) & - & $14.4(6.9)$ & $20.7(8.7)$ & $24.0(7.8)$ & $23.6(7.7)$ & $24.8(7.3)$ & 0.006 \\
\hline Systolic BP (mm Hg) & $134.0(20.7)$ & $135.5(20.2)$ & $135.6(21.4)$ & $134.9(19.3)$ & $133.2(23.6)$ & $134.2(19.6)$ & 0.359 \\
\hline Diastolic BP (mm Hg) & $84.3(13.8)$ & $86.2(13.4)$ & $85.3(14.1)$ & $83.8(12.7)$ & $83.3(15.5)$ & $84.1(13.1)$ & 0.260 \\
\hline Total serum cholesterol $(\mathrm{mmol} / \mathrm{l})$ & $5.90(1.28)$ & $6.12(1.27)$ & $6.14(1.35)$ & $6.20(1.29)$ & $6.26(1.56)$ & $6.27(1.33)$ & 0.865 \\
\hline Serum triglycerides $(\mathrm{mmol} / \mathrm{l})$ & $1.94(1.17)$ & $2.07(1.28)$ & $2.10(1.28)$ & $2.05(1.27)$ & $1.95(1.16)$ & $2.02(1.29)$ & 0.342 \\
\hline Physical activity leisure $¥$ & $2.32(0.76)$ & $2.27(0.73)$ & $2.19(0.72)$ & $2.15(0.70)$ & $2.03(0.68)$ & $2.03(0.71)$ & 0.982 \\
\hline BMI $\left(\mathrm{kg} / \mathrm{m}^{2}\right)$ & $25.3(2.9)$ & $25.9(2.9)$ & $26.0(3.0)$ & $24.7(3.0)$ & $24.7(3.1)$ & $24.9(3.1)$ & 0.296 \\
\hline Height $(\mathrm{cm})$ & $176.3(6.8)$ & $176.0(6.5)$ & $175.6(6.8)$ & $175.0(6.8)$ & $174.5(7.0)$ & $175.4(6.7)$ & 0.016 \\
\hline Disability pension (\%) & $3.4(0.2)$ & $2.8(0.2)$ & $2.9(0.2)$ & $4.5(0.2)$ & $6.4(0.4)$ & $3.8(0.2)$ & 0.019 \\
\hline Sick leave (\%) & $2.6(0.2)$ & $3.1(0.2)$ & $4.4(0.2)$ & $4.3(0.2)$ & $7.2(0.3)$ & $4.9(0.2)$ & 0.053 \\
\hline Family history of CHD (\%)§ & $25.6(4.4)$ & $30.6(4.6)$ & $26.4(4.4)$ & $26.6(4.4)$ & $32.9(4.7)$ & $29.5(4.6)$ & 0.386 \\
\hline \multicolumn{8}{|l|}{ Women ( $n=25$ 698) } \\
\hline Age (years) & $42.2(6.5)$ & $41.3(6.7)$ & $40.2(7.6)$ & $40.8(7.3)$ & $41.6(6.7)$ & $40.9(6.9)$ & 0.256 \\
\hline Cigarette consumption (no/day) & - & $8.5(5.2)$ & $9.8(5.6)$ & $9.2(3.8)$ & $8.6(2.5)$ & $16.4(5.2)$ & $<0.001$ \\
\hline Duration of smoking (years) & - & $10.4(6.2)$ & $15.5(7.5)$ & $19.4(7.3)$ & $20.6(7.3)$ & $21.6(6.9)$ & 0.173 \\
\hline Systolic BP (mm Hg) & $131.3(21.0)$ & $128.3(19.9)$ & $127.7(22.3)$ & $128.0(20.0)$ & $129.8(16.6)$ & $127.1(20.7)$ & 0.142 \\
\hline Diastolic BP $(\mathrm{mm} \mathrm{Hg})$ & $82.1(12.3)$ & 80.7 (12.3) & $79.8(14.0)$ & $80.0(12.3)$ & $80.0(11.4)$ & $80.0(12.9)$ & 0.978 \\
\hline Total serum cholesterol $(\mathrm{mmol} / \mathrm{l})$ & $6.05(1.27)$ & $5.97(1.31)$ & $6.00(1.43)$ & $6.20(1.38)$ & $6.11(1.23)$ & $6.22(1.37)$ & 0.394 \\
\hline Serum triglycerides $(\mathrm{mmol} / \mathrm{l})$ & $1.33(0.74)$ & $1.32(0.85)$ & $1.42(0.84)$ & $1.50(0.90)$ & $1.41(0.81)$ & $1.52(0.90)$ & 0.171 \\
\hline Physical activity leisureł & $2.01(0.57)$ & $2.02(0.56)$ & $1.98(0.56)$ & $1.95(0.57)$ & $1.87(0.60)$ & $1.84(0.59)$ & 0.588 \\
\hline BMI $\left(\mathrm{kg} / \mathrm{m}^{2}\right)$ & $25.1(4.0)$ & $24.6(3.7)$ & $25.0(4.1)$ & $23.7(3.6)$ & $24.0(3.8)$ & $23.7(3.7)$ & 0.448 \\
\hline Height $(\mathrm{cm})$ & $162.8(6.1)$ & $163.6(6.1)$ & $162.7(6.2)$ & $162.7(5.9)$ & $161.6(6.0)$ & $163.4(6.0)$ & 0.001 \\
\hline Disability pension (\%) & $4.2(0.2)$ & $2.5(0.2)$ & $4.0(0.2)$ & $4.6(0.2)$ & $8.7(0.3)$ & $4.7(0.2)$ & 0.044 \\
\hline Sick leave (\%) & $3.0(0.2)$ & $3.7(0.2)$ & $4.2(0.2)$ & $5.0(0.2)$ & $10.2(0.3)$ & $5.6(0.2)$ & 0.034 \\
\hline Family history of $\mathrm{CHD}(\%) \S$ & $29.9(4.6)$ & $32.7(4.7)$ & $31.1(4.6)$ & $31.7(4.7)$ & $33.1(4.7)$ & $36.7(4.8)$ & 0.333 \\
\hline
\end{tabular}

$\mathrm{BMI}$, body mass index; BP, blood pressure; $\mathrm{CHD}$, coronary heart disease.

Values are mean (SD) or \% (SD).

Table 4 shows the number of participants in each category.

*Participants not reporting cardiovascular disease, diabetes or treatment for hypertension, or symptoms of angina pectoris or atherosclerosis obliterans.

tp Values represent differences between the reducers and the continuous heavy smokers.

$\ddagger$ Physical activity during leisure was graded $1-4$, with 4 denoting the heaviest activity.

$\S$ One or more of parents or siblings reported to have had a heart infarction or angina pectoris.

The most important elements of the screening programme were kept unchanged throughout all screenings-in particular, that part of the questionnaire covering smoking habits.

\section{The study population}

For each individual who underwent two or more examinations, paired results were selected according to the following priority, on the basis of attendance to the

- first and second screenings $(\mathrm{n}=53$ 078);

- first and third screenings $(n=1339)$; and

- second and third screenings $(\mathrm{n}=7075)$.

Consequently, there was a total of 61492 people (30 956 men and 30536 women) who had results from two examinations.

The follow-up period started from the last examination.

Table 2 Mean number of cigarettes per day at first and last examinations in moderate smokers, reducers and heavy smokers, by sex

\begin{tabular}{lcrl}
\hline & $\begin{array}{l}\text { Moderate } \\
\text { smokers }\end{array}$ & Reducers & $\begin{array}{l}\text { Heavy } \\
\text { smokers }\end{array}$ \\
\hline Men & & & \\
$\quad$ First examination & 9.2 & 22.9 & 18.8 \\
$\quad$ Last examination & 10.6 & 9.7 & 18.3 \\
& & & \\
Women & & & \\
$\quad$ First examination & 8.1 & 19.5 & 17.0 \\
$\quad$ Last examination & 9.2 & 8.6 & 16.4 \\
\hline
\end{tabular}

Table 4 shows the number of participants in each category.

\section{Exclusions}

We excluded the following people: men and women who at the last examination reported a history of myocardial infarction, angina pectoris, stroke, diabetes, atherosclerosis of legs, treatment for hypertension, use of glyceryl trinitrate and symptoms indicative of angina pectoris or atherosclerosis obliterans, totalling 6506 people. They were excluded to avoid the problem of reverse causality that might occur if people reduced smoking owing to illness. Also, 1594 men smoking a pipe at the last examination were excluded. The few women who smoked a pipe and the few men and women who smoked cigars were disregarded. Also, 1884 people who started smoking between the first and second examination were excluded, as were 298 people for unspecified reasons. Consequently, the total number of people excluded were 10282 (5997 men and 4285 women).

Thus, 24959 men and 26251 women remained as participants for analysis. All of them underwent two examinations, and at the time of the last investigation they reported neither a history related to cardiovascular disease or diabetes nor symptoms indicative of angina pectoris or atherosclerosis obliterans. They were present or previously daily smokers of only cigarettes, or had never smoked cigarettes daily. For a negligible number of participants, information was missing on some of the confounding variables.

\section{Quantity of daily cigarette consumption}

The attending participants reported the actual number of cigarettes smoked per day in a special box in the questionnaire. Here, they were allowed to cite a range, such as 1015 cigarettes. 
Table 3 Determination of serum thiocyanate at the last examination, by category of smoking

\begin{tabular}{|c|c|c|c|c|c|c|c|}
\hline & $\begin{array}{l}\text { Never } \\
\text { smokers }\end{array}$ & Ex-smokers & Quitters & $\begin{array}{l}\text { Moderate } \\
\text { smokers }\end{array}$ & Reducers & $\begin{array}{l}\text { Heavy } \\
\text { smokers }\end{array}$ & p Value \\
\hline \multicolumn{8}{|l|}{$\operatorname{Men}(n=5851)^{*}$} \\
\hline Participants (n) & 1168 & 1038 & 666 & 1347 & 139 & 1493 & \\
\hline $\begin{array}{l}\text { Mean (SD) serum thiocyanate } \\
(\mu \mathrm{mol} / \mathrm{l})\end{array}$ & 30.5 (15.7) & $28.7(17.2)$ & $29.6(18.0)$ & $65.2(27.6)$ & $66.8(28.1)$ & $75.8(30.7)$ & 0.001 \\
\hline \multicolumn{8}{|l|}{ Women $(n=5630)^{*}$} \\
\hline Participants (n) & 2213 & 643 & 403 & 1747 & 45 & 579 & \\
\hline $\begin{array}{l}\text { Mean (SD) serum thiocyanate } \\
(\mu \mathrm{mol} / \mathrm{l})\end{array}$ & $28.5(13.4)$ & $31.8(16.8)$ & $34.9(19.5)$ & $76.2(31.0)$ & $81.3(33.4)$ & $91.0(35.4)$ & 0.074 \\
\hline
\end{tabular}

*Participants not reporting cardiovascular disease, diabetes or treatment for hypertension, or symptoms of angina pectoris or atherosclerosis obliterans. tp Values represent differences between the reducers and the continuous heavy smokers.

At the examination site, the nurses carefully checked through the questionnaire with the participants. Factorymade and hand-rolled cigarettes had to be counted together. The nurses were instructed that one pack of tobacco for hand rolling ( $50 \mathrm{~g}$ ) equalled 50 cigarettes. For those who gave a range of consumption, we used the highest figure.

\section{Categories of participants}

To compare our results with those of the Danish study, ${ }^{1}$ we found it suitable to apply the categories used by Godtfredsen et al, ${ }^{1}$ with a slight modification as follows:
- Never smokers: People who at both examinations stated that they did not smoke cigarettes daily, and at the first examination said that they had never done so previously.

- Ex-smokers: People who at both examinations stated that they did not smoke cigarettes daily, and at the first examination said that they had done so previously.

- Quitters: People who at the first examination stated that they smoked cigarettes daily, but had quit smoking at the time of the last examination.

- Moderate smokers: People who at the first examination stated that they smoked 1-14 cigarettes per day, and at the last examination said that they smoked cigarettes daily.

Table 4 Number of participants* and person-years; and deaths from all causes, cardiovascular disease, ischaemic heart disease, smoking-related cancer or lung cancer, number and per 100000 person-years, age adjusted, by sex and smoking category

\begin{tabular}{|c|c|c|c|c|c|c|}
\hline & $\begin{array}{l}\text { Never } \\
\text { smokers }\end{array}$ & Ex-smokers & Quitters & $\begin{array}{l}\text { Moderate } \\
\text { smokers }\end{array}$ & Reducers & $\begin{array}{l}\text { Heavy } \\
\text { smokers }\end{array}$ \\
\hline \multicolumn{7}{|l|}{ Men (n=24 959) } \\
\hline Participants (n) & 6716 & 5140 & 2676 & 5340 & 348 & 4739 \\
\hline Number of person-years & 141145 & 109381 & 56512 & 109562 & 6925 & 94452 \\
\hline \multicolumn{7}{|l|}{ All causes } \\
\hline Deaths & 663 & 683 & 409 & 1264 & 103 & 1386 \\
\hline Deaths per 100000 person-years & 507 & 575 & 727 & 1153 & 1498 & 1462 \\
\hline \multicolumn{7}{|l|}{ Cardiovascular disease } \\
\hline Deaths & 233 & 238 & 168 & 542 & 41 & 534 \\
\hline Deaths per 100000 person-years & 184 & 199 & 295 & 494 & 599 & 563 \\
\hline \multicolumn{7}{|l|}{ Ischaemic heart disease } \\
\hline Deaths & 151 & 160 & 114 & 394 & 26 & 381 \\
\hline Deaths per 100000 person-years & 120 & 133 & 200 & 361 & 393 & 401 \\
\hline \multicolumn{7}{|l|}{ Smoking-related cancer } \\
\hline Deaths & 111 & 120 & 79 & 269 & 19 & 354 \\
\hline Deaths per 100000 person-years & 85 & 99 & 142 & 247 & 279 & 371 \\
\hline \multicolumn{7}{|l|}{ Lung cancer } \\
\hline Deaths & 7 & 20 & 16 & 128 & 10 & 189 \\
\hline Deaths per 100000 person-years & 5 & 16 & 29 & 116 & 134 & 199 \\
\hline \multicolumn{7}{|l|}{ Women $(n=26251)$} \\
\hline Participants (n) & 12657 & 2954 & 1584 & 7098 & 127 & 1831 \\
\hline Number of person-years & 275859 & 63718 & 34265 & 151963 & 2558 & 38306 \\
\hline \multicolumn{7}{|l|}{ All causes } \\
\hline Deaths & 954 & 205 & 154 & 1002 & 27 & 318 \\
\hline Deaths per 100000 person-years & 332 & 329 & 492 & 690 & 1090 & 873 \\
\hline \multicolumn{7}{|l|}{ Cardiovascular disease } \\
\hline Deaths & 186 & 36 & 36 & 291 & 5 & 84 \\
\hline Deaths per 100000 person-years & 63 & 59 & 118 & 203 & 207 & 236 \\
\hline \multicolumn{7}{|l|}{ Ischaemic heart disease } \\
\hline Deaths & 98 & 14 & 25 & 152 & 3 & 43 \\
\hline Deaths per 100000 person-years & 34 & 22 & 80 & 106 & 72 & 120 \\
\hline \multicolumn{7}{|l|}{ Smoking-related cancer } \\
\hline Deaths & 112 & 27 & 19 & 222 & 8 & 82 \\
\hline Deaths per 100000 person-years & 40 & 44 & 59 & 153 & 328 & 222 \\
\hline \multicolumn{7}{|l|}{ Lung cancer } \\
\hline Deaths & 11 & 7 & 6 & 119 & 2 & 57 \\
\hline Deaths per 100000 person-years & 4 & 10 & 20 & 82 & 48 & 153 \\
\hline
\end{tabular}

*Participants not reporting cardiovascular disease, diabetes or treatment for hypertension, or symptoms of angina pectoris or atherosclerosis obliterans at the last examination. 
- Reducers: People who at the first examination stated a consumption of $\geqslant 15$ cigarettes per day, and at the last examination reported a consumption of at least $50 \%$ less cigarettes per day.

- Heavy smokers: People who at the first examination stated a consumption of $\geqslant 15$ cigarettes per day, and at the last examinations did not fall into the categories of reducers or quitters.

\section{Determination of serum thiocyanate}

In 1976, determination of serum thiocyanate was introduced at the initial screening in one of the counties. Methods and quality assurance have been described by Foss and LundLarsen, ${ }^{15}$ who have also reported the results from the initial survey. Tobacco smoke contains hydrogen cyanide, which is absorbed in the lungs and then metabolised to thiocyanate. Owing to its long half life, serum thiocyanate has the advantage that it better reflects the average exposure to tobacco smoke during the previous couple of weeks than the exposure on a given day. The authors underline, however, that diet also contributes to the level of thiocyanate in serum; therefore, this level is not a specific indicator for tobacco smoking. A single determination can neither confirm nor weaken a statement on current individual tobacco consumption.

Analyses of serum thiocyanate in large population groups, however, will give valuable information on the group's tobacco consumption. This is shown by results from the initial screening, which show a remarkable dose-response relationship between mean serum thiocyanate concentration and mean cigarette consumption of the group, based on questionnaire answers of the participants. ${ }^{15}$

At the second screening, serum thiocyanate was determined only in Finnmark county; therefore, we have information on serum thiocyanate for not more than 5851 men and 5630 women-that is, $22.4 \%$ of the total number of the participants.

\section{End points}

We carried out a mortality follow-up by linking our records with the National Register of Causes of Death, using the 11digit personal identification number as record linkage. Each person accrued person-years from the day of the last examination until the date of death, date of emigration or 31 December 2003.

In addition to deaths from all causes, we studied deaths from the following:

- Cardiovascular disease: International classification of diseases (ICD), 8th edition: 390-444.1, 444.3-458; ICD9: 390-459; ICD10: I00-99

- Ischaemic heart disease: ICD8 and ICD9: 410-414; ICD10: I20-25

- Smoking-related cancer: Types of cancer that the International Agency for Research on Cancer has classed as liable to be caused by smoking, and later applied by Doll et al. ${ }^{16}$ Thus, the following types of cancer were included:

- Lip, oral cavity and pharynx: ICD8 and ICD9: 140-149; ICD 10: C00-14

- Nose and nasal sinuses: ICD8 and ICD9: 160; ICD10: C30-31

- Larynx, trachea, bronchus and lung: ICD8 and ICD9: 161-162; ICD10: C32-34

- Oesophagus: ICD8 and ICD9: 150; ICD10: C15

- Stomach: ICD8 and ICD9: 151; ICD10: C16

- Pancreas: ICD8 and ICD9: 157; ICD10: C25

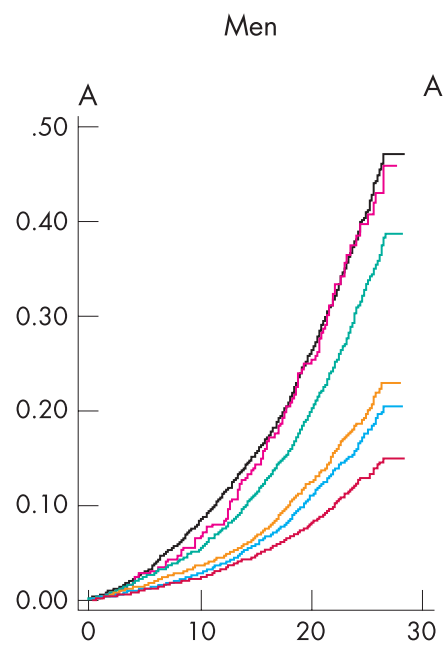

All causes

Women
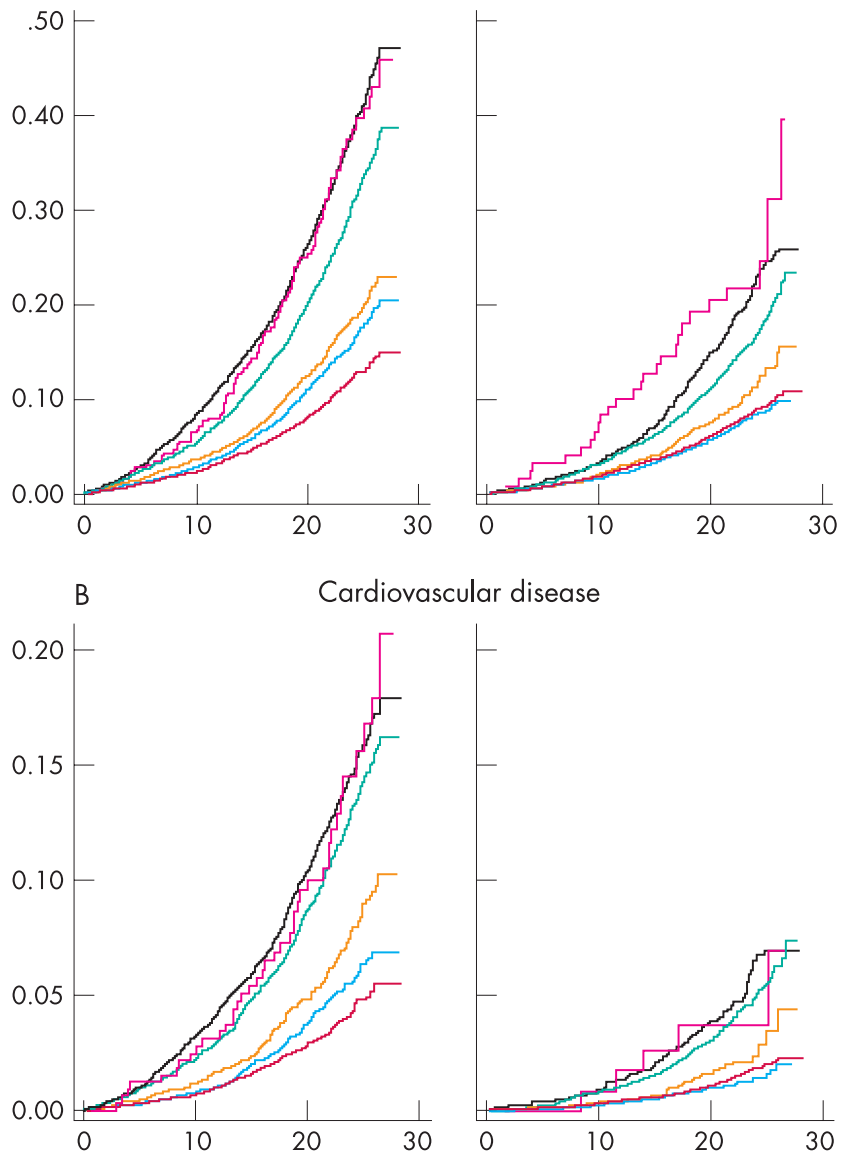

ular disease
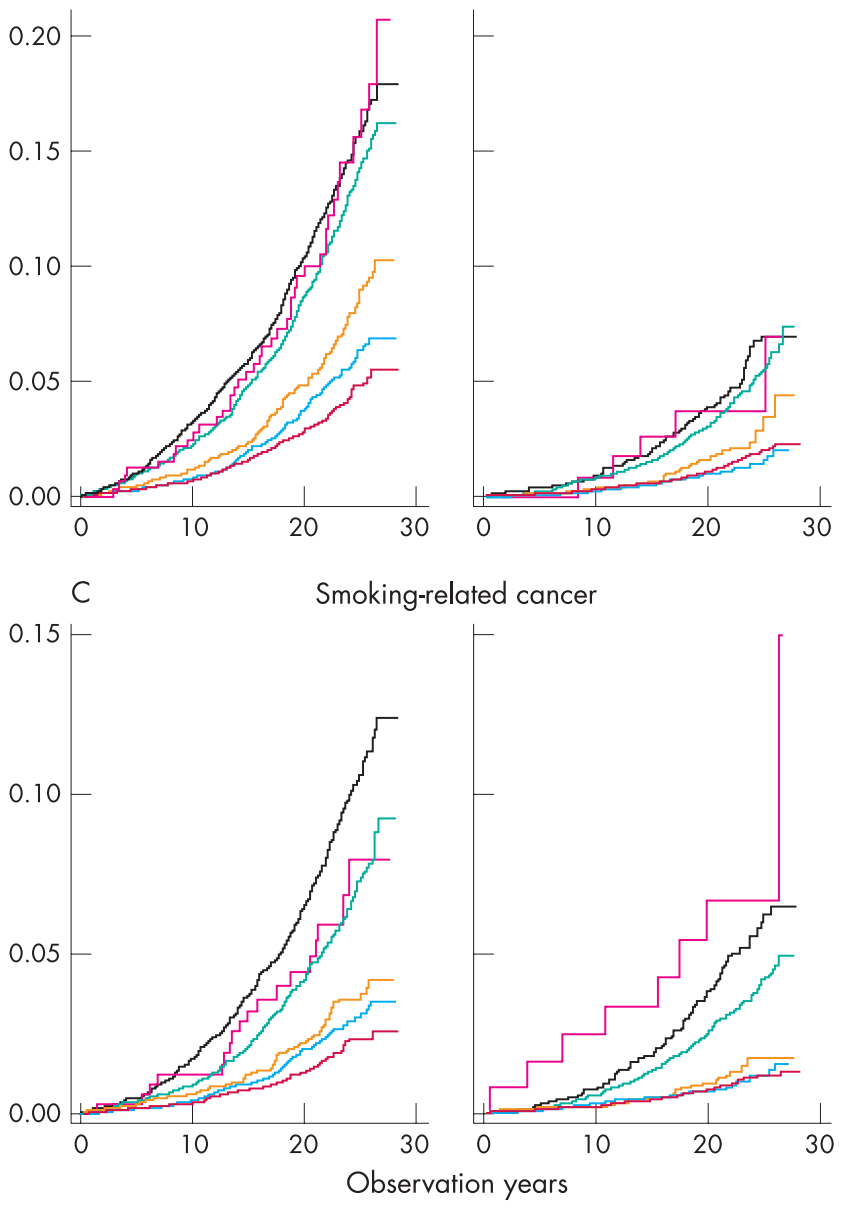

Categories

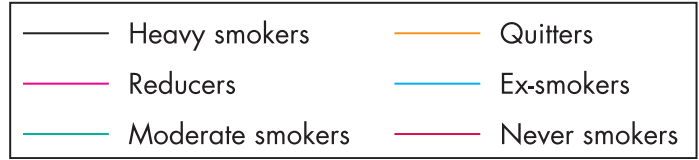

Figure 1 Deaths from (A) all causes, (B) cardiovascular disease and (C) smoking-related cancer, as cumulative proportions of male and female participants in each category, by time of death. Nelson-Aalen cumulative hazard estimates. The $\mathrm{x}$ axis shows the observation years and the $y$ axis shows the cumulative proportions.

- Liver: ICD8: 155, 197.8; ICD9: 155; ICD10: C22

- Kidney and renal pelvis: ICD8 and ICD9: 189.0-1; ICD10: C64-65 
- Bladder and ureter: ICD8 and ICD9: 188; ICD10: C6667

- Myeloid leukaemia: ICD8 and ICD9: 205; ICD10: C92

- Lung cancer: ICD8 and ICD9: 161-162; ICD10: C32-34.

\section{Statistical methods}

Comparisons of baseline factors between heavy cigarette smokers and the reducers were made by the test or the $\chi^{2}$ test. Adjustments for age were carried out by the direct method, by applying the rates in 1-year age groups in the smoking categories during the observation years in the total study population. This was carried out separately for men and women. Relative risks adjusted for confounders were estimated using the Cox's proportional hazards model. Age attained was used as the time variable. The proportional hazards assumption was evaluated by visual inspection of the plots of $\log$ (person-years) against-log-log(survival probability). The lines in the smoking categories were fairly parallel. In the Nelson-Aalen plots, person-years was the time variable. Values of $p<0.05$ were considered significant.

\section{RESULTS}

Table 1 shows background characteristics of the participants at the start of follow-up.

In both sexes, never smokers, ex-smokers and quitters had a lower mean cholesterol level and a higher degree of leisure physical activity than smokers from any category. Exsmokers had a shorter duration of smoking than present smokers; duration in quitters was between that in smokers and that in ex-smokers. In all smoking categories, the duration of smoking was 3-5 years less in women than in men.

Comparing reducers with heavy smokers, reducers had a considerably lower stature and a higher frequency of disability pension (both sexes). Male reducers had a shorter duration of smoking, and female reducers had a higher frequency of sick leave.
Table 2 shows the mean number of cigarettes at the first and last examinations in heavy smokers, reducers and moderate smokers.

At the last examination, reducers had a daily cigarette consumption that was 58\% lower in men and 56\% lower in women compared with consumption at the first examination. In both sexes, moderate smokers had a slightly higher and heavy smokers had a slightly lower daily consumption at the last examination than at the first examination.

Table 3 shows the mean serum thiocyanate values at the time of the last examination in participants in whom thiocyanate was determined.

In both sexes, there are clearly higher mean serum thiocyanate levels in the smokers than in never smokers and previous smokers. Both male and female reducers have mean values that are lower than in heavy smokers, the difference being statistically significant for men $(p=0.001)$, but not for women $(p=0.074)$. Male and female reducers have mean thiocyanate values that are slightly above those of the moderate smokers. They report a cigarette consumption, however, which on average is slightly below those of the moderate smokers (table 2).

Table 4 shows the age-adjusted mortality from any cause, cardiovascular disease, ischaemic heart disease, smokingrelated cancer or lung cancer, by sex and smoking category.

In men, the mortality among reducers was lower than that among heavy smokers only for smoking-related cancer and lung cancer. These differences were not beyond chance. Only a few cause-specific deaths were seen in women. Mortality from any cause, however, was non-significantly higher in reducers than in heavy smokers.

Figure 1 shows the cumulative proportions of deaths from all causes, cardiovascular disease and smoking-related cancer, by time of death. For all causes in men, the reducers have slightly lower death rates than heavy smokers during the first 15 years, whereas afterwards the reducers catch up with the heavy smokers. For women, reducers have higher total mortality than heavy smokers during the whole period. For cardiovascular disease in both sexes, there is on the whole no distinct difference between reducers and heavy

Table 5 Adjusted relative risk* $(95 \% \mathrm{Cl})$ of death from all causes, cardiovascular disease, ischaemic heart disease, smokingrelated cancer or lung cancer, by smoking category, sex individually and both sexes together, with heavy smokers as reference (23 798 male and 25698 female participants aged $20-49$ at initial screeningt)

\begin{tabular}{|c|c|c|c|c|c|c|}
\hline Sex category, deaths from & $\begin{array}{l}\text { Never } \\
\text { smokers }\end{array}$ & Ex-smokers & Quitters & $\begin{array}{l}\text { Moderate } \\
\text { smokers }\end{array}$ & Reducers & $\begin{array}{l}\text { Heavy } \\
\text { smokers }\end{array}$ \\
\hline \multicolumn{7}{|c|}{ Men ( $n=23798$ aged $20-49$ years $) \dagger$} \\
\hline All causes & $0.34(0.31$ to 0.38$)$ & $0.36(0.33$ to 0.40$)$ & $0.45(0.40$ to 0.51$)$ & $0.77(0.71$ to 0.83$)$ & $0.99(0.80$ to 1.22$)$ & 1.00 \\
\hline Cardiovascular disease & $0.31(0.26$ to 0.36$)$ & $0.31(0.26$ to 0.36$)$ & $0.46(0.39$ to 0.55$)$ & $0.85(0.75$ to 0.96$)$ & $1.04(0.75$ to 1.43$)$ & 1.00 \\
\hline Ischaemic heart disease & $0.29(0.24$ to 0.35$)$ & $0.30(0.25$ to 0.37$)$ & $0.45(0.36$ to 0.56$)$ & 0.89 (0.77 to 1.03 ) & $0.94(0.63$ to 1.41$)$ & 1.00 \\
\hline Smoking-related cancer & $0.23(0.19$ to 0.29$)$ & $0.26(0.21$ to 0.33$)$ & $0.33(0.26$ to 0.43$)$ & $0.65(0.55$ to 0.76$)$ & $0.72(0.45$ to 1.18$)$ & 1.00 \\
\hline Lung cancer & $0.03(0.01$ to 0.06$)$ & $0.09(0.05$ to 0.14$)$ & $0.14(0.08$ to 0.23$)$ & $0.57(0.45$ to 0.72$)$ & $0.71(0.36$ to 1.39$)$ & 1.00 \\
\hline \multicolumn{7}{|c|}{ Women ( $n=25698$ aged $20-49$ years) $\dagger$} \\
\hline All causes & $0.35(0.31$ to 0.40$)$ & $0.37(0.31$ to 0.44$)$ & $0.53(0.43$ to 0.65$)$ & $0.77(0.68$ to 0.88$)$ & $1.11(0.74$ to 1.67$)$ & 1.00 \\
\hline Cardiovascular disease & $0.24(0.19$ to 0.32$)$ & $0.25(0.16$ to 0.37$)$ & $0.47(0.31$ to 0.69$)$ & $0.85(0.66$ to 1.10$)$ & $0.86(0.35$ to 2.13$)$ & 1.00 \\
\hline Ischaemic heart disease & $0.28(0.19$ to 0.41$)$ & $0.20(0.11$ to 0.37$)$ & $0.68(0.41$ to 1.12$)$ & $0.92(0.65$ to 1.32$)$ & $1.13(0.35$ to 3.67$)$ & 1.00 \\
\hline Smoking-related cancer & $0.16(0.12$ to 0.22$)$ & $0.18(0.12$ to 0.29$)$ & $0.24(0.14$ to 0.40$)$ & $0.64(0.49$ to 0.83$)$ & $1.40(0.68$ to 2.90$)$ & 1.00 \\
\hline Lung cancer & 0.02 (0.01 to 0.04$)$ & $0.07(0.03$ to 0.16$)$ & $0.13(0.05$ to 0.29$)$ & $0.50(0.36$ to 0.69$)$ & $0.51(0.12$ to 2.08$)$ & 1.00 \\
\hline \multicolumn{7}{|l|}{ Both sexes } \\
\hline All causes & $0.34(0.32$ to 0.37$)$ & $0.37(0.34$ to 0.40$)$ & $0.47(0.43$ to 0.52$)$ & $0.76(0.72$ to 0.82$)$ & $1.02(0.84$ to 1.22$)$ & 1.00 \\
\hline Cardiovascular disease & $0.28(0.25$ to 0.33$)$ & $0.30(0.26$ to 0.34$)$ & $0.46(0.39$ to 0.54$)$ & $0.86(0.77$ to 0.96$)$ & $1.02(0.75$ to 1.39$)$ & 1.00 \\
\hline Ischaemic heart disease & 0.28 (0.24 to 0.33$)$ & 0.29 (0.24 to 0.34$)$ & 0.48 (0.39 to 0.58$)$ & 0.89 (0.78 to 1.02$)$ & $0.96(0.65$ to 1.41$)$ & 1.00 \\
\hline Smoking-related cancer & $0.20(0.17$ to 0.24$)$ & $0.25(0.20$ to 0.30$)$ & $0.31(0.25$ to 0.39$)$ & $0.66(0.58$ to 0.76$)$ & $0.86(0.57$ to 1.28$)$ & 1.00 \\
\hline Lung cancer & $0.03(0.02$ to 0.04$)$ & 0.08 (0.06 to 0.12$)$ & $0.14(0.09$ to 0.21$)$ & $0.55(0.45$ to 0.66$)$ & $0.66(0.36$ to 1.21$)$ & 1.00 \\
\hline
\end{tabular}

*Adjusted for age, systolic and diastolic blood pressure, total serum cholesterol, serum triglycerides, physical activity during leisure, body mass index $\left(\mathrm{kg} / \mathrm{m}^{2}\right)$, height, disability pension, sickness leave and family history of coronary heart disease recorded at the last examination. In the section covering both sexes, adjustmentsare made also for sex.

†Participants not reporting cardiovascular disease, diabetes or treatment for hypertension, or symptoms of angina pectoris or atherosclerosis obliterans at the last examination. 
Table 6 Relative risk* $(95 \% \mathrm{Cl})$ of death from all causes in reducers at the second examination who attended the third examination, by group at the third examination, with sustained heavy smokers as reference, in both sexes

\begin{tabular}{|c|c|c|c|c|}
\hline & \multicolumn{3}{|c|}{ Reducers at second examination, group at third examination } & \multirow{2}{*}{$\begin{array}{l}\text { Sustained heavy } \\
\text { smokers from } \\
\text { second to the } \\
\text { third examination }\end{array}$} \\
\hline & New quitters & $\begin{array}{l}\text { Sustained } \\
\text { reducers }\end{array}$ & Increasers & \\
\hline Relative risk & $0.47(0.21$ to 1.04$)$ & $1.16(0.73$ to 1.85$)$ & $1.23(0.90$ to 1.69$)$ & 1.00 \\
\hline Participants $(n=271) \dagger$ & 37 & 69 & 165 & 3574 \\
\hline Number of deaths & 6 & 18 & 42 & 818 \\
\hline Men (\%) & 86 & 75 & 70 & 72 \\
\hline \multicolumn{5}{|c|}{ Mean (SD) daily cigarette consumption } \\
\hline First examination & $21.8(6.4)$ & $23.6(8.8)$ & $20.6(6.7)$ & $18.0(4.6)$ \\
\hline Second examination & $9.1(3.3)$ & $10.0(4.0)$ & $9.2(3.6)$ & $17.5(6.0)$ \\
\hline Third examination & 0 & $10.4(4.8)$ & $17.2(6.4)$ & $18.3(6.6)$ \\
\hline
\end{tabular}

smokers. For smoking-related cancer, a clear difference can be seen between the sexes. In men, the reducers have lower death rates than the heavy smokers, whereas the reverse picture is seen in women. For the remaining smoking categories, the mortality levels are as expected. For female ex-smokers, however, the curve falls slightly below that for never smokers. Mortality due to cardiovascular disease among female heavy smokers is comparable with that in men who have quit smoking.

Table 5 shows the adjusted relative risks of death with heavy smokers as reference. Adjustments are made for age, systolic and diastolic blood pressure, serum total cholesterol, serum triglycerides, physical activity during leisure, body mass index $\left(\mathrm{kg} / \mathrm{m}^{2}\right)$, height, disability pension, sickness leave and recorded coronary heart disease in the family. Table 5 also gives the relative risk for men and women together, to make comparisons with the reports by Godtfredsen et al. ${ }^{134}$ Here adjustments are also made for sex.

For both sexes, reducers have almost the same adjusted relative risk for death from any cause as heavy smokers. For cardiovascular disease and ischaemic heart disease, the adjusted risk in reducers is not significantly different from that in heavy smokers ( see table 5). For smoking-related cancer, the adjusted relative risk is lower for male reducers but higher for female reducers compared with the heavy smokers, but neither difference is statistically significant. For both men and women, the adjusted relative risk for lung cancer is clearly lower than in heavy smokers (29\% lower in men, $49 \%$ in women), but does not reach statistical significance. In both men and women, and in all cause groups, relative risks decrease regularly: from reducers, through moderate smokers, quitters and ex-smokers, to never smokers. An exception is cardiovascular deaths in women, where we find a somewhat higher relative risk in never smokers than in ex-smokers.

As mentioned earlier, a third screening was carried out in all three counties. In Finnmark (25\% of the total study population), this screening took place 10 years after the second screening; in the other two counties, 5 years after the second. Of the 475 reducers at the second examination, 271 attended the third examination. The main reason for the lower number of participants was that only a $10 \%$ random sample of the oldest 5-year age group was invited to the third examination.

We grouped these 271 participants by their status at the third examination:

- New quitters: Those who quit smoking entirely between the second and third examinations

- Sustained reducers: Those who were daily smokers at the third examination, and still reported a consumption of at least $50 \%$ less cigarettes per day compared with the first examination

- Increasers: Those who were daily smokers at the third examination, but reported to have a daily cigarette consumption that had increased so much from the second examination that they no longer fulfilled the criteria of reducers.

As a reference group, we introduced sustained heavy smokers-that is, smokers with a daily cigarette consumption of $\geqslant 15$ cigarettes at all three examinations.

Table 7 Relative risk $(95 \% \mathrm{Cl})^{*}$ of dying from all causes and from cardiovascular disease, ischaemic heart disease, smoking-related cancer or lung cancer in daily smokers at both examinations, per 10 decrease in cigarette consumption from the first to the last examination ( $n=24959$ men and 26251 women)t

\begin{tabular}{|c|c|c|c|c|}
\hline \multirow[b]{2}{*}{ Deaths from } & \multicolumn{2}{|c|}{ Heavy smokers } & \multicolumn{2}{|l|}{ All smokers } \\
\hline & $\begin{array}{l}\text { Number of } \\
\text { deaths }\end{array}$ & $\begin{array}{l}\text { Relative risks }(95 \% \mathrm{Cl}) \\
\text { per } 10 \text { cigarette } \\
\text { consumption decrease }\end{array}$ & $\begin{array}{l}\text { Number of } \\
\text { deaths }\end{array}$ & $\begin{array}{l}\text { Relative risks }(95 \% \mathrm{Cl}) \\
\text { per } 10 \text { cigarette } \\
\text { consumption decrease }\end{array}$ \\
\hline All causes & 1809 & 0.97 (0.90 to 1.04$)$ & 4042 & 1.00 (0.94 to 1.05$)$ \\
\hline Cardiovascular disease & 650 & 0.90 (0.79 to 1.03$)$ & 1479 & 0.98 (0.89 to 1.08$)$ \\
\hline Ischaemic heart disease & 447 & 0.85 (0.73 to 1.01$)$ & 989 & $0.97(0.87$ to 1.10$)$ \\
\hline Smoking-related cancer & 453 & 0.91 (0.79 to 1.06 ) & 935 & 0.99 (0.89 to 1.11$)$ \\
\hline Lung cancer & 253 & 0.97 (0.80 to 1.18 ) & 497 & 1.01 (0.87 to 1.17$)$ \\
\hline
\end{tabular}

*Adjusted for sex and consumption level.

†Participants not reporting cardiovascular disease, diabetes or treatment for hypertension, or symptoms of angina pectoris or atherosclerosis obliterans. 
Table 8 Comparison of the relative risks $(95 \% \mathrm{Cl})$ in reducers $v$ heavy smokers from the study of the three Norwegian counties with those presented from the Copenhagen Centre for Prospective Population Studies, both sexes*

\begin{tabular}{lll}
\hline End point & Copenhagen, Denmark & Three counties, Norway \\
\hline All deaths & $1.02(0.89$ to 1.17$)$ & $1.02(0.84$ to 1.22$)$ \\
Cardiovascular disease & $1.01(0.76$ to 1.35$)$ & $1.02(0.75$ to 1.39$)$ \\
Ischaemic heart disease & $1.15(0.94$ to 1.40$)$ & $0.96(0.65$ to 1.41$)$ \\
Smoking-related cancer & $0.91(0.63$ to 1.31$)$ & $0.86(0.57$ to 1.28$)$ \\
Lung cancer & $0.73(0.54$ to 0.98$)$ & $0.66(0.36$ to 1.21$)$ \\
\hline
\end{tabular}

*In the Norwegian counties, the risks are based on deaths only; in Copenhagen the same applies for cardiovascular disease and smoking-related cancer. In Copehagen, ischaemic heart disease refers to fatal and non-fatal endpoints and lung cancer to incidence.

Table 6 shows the relative risk of death from all causes in the three groups mentioned, with sustained heavy smokers as reference (both sexes together, but adjusted for sex).

Relative risks in none of the three groups differ significantly from the reference group. The tendency of new quitters to have the same relative risk as quitters at the second examination is clear. Sustained reducers have a relative risk in line with the sustained heavy smokers, whereas increasers have an even higher relative risk.

Table 6 gives also the mean daily cigarette consumption in all groups at all three examinations. At the second examination, this mean differed only slightly between the three groups. At the third examination, the mean remained at the same level in sustained reducers, nearly doubled in those who increased smoking, and went down to zero in new quitters. In sustained heavy smokers, the mean consumption was almost constant at all three examinations.

So far, we have concentrated on participants who were heavy smokers, who at the second examination reported a consumption of at least $50 \%$ less cigarettes per day. As a last approach, we present relative risk by degree of change in daily cigarette consumption between the first and the last examinations. This is done by running Cox's proportional hazards analyses among the daily smokers at both the first and last examinations, with sex, consumption level and consumption change as covariates. Consumption level was defined as the mean number of cigarettes at the first and last examinations; consumption change was defined as the difference between number of cigarettes at the first and last examinations.

Table 7 shows the relative risks of dying from any cause and from specified smoking-related diseases associated with a per 10 cigarette decrease in cigarette consumption, adjusted for sex and consumption level, for heavy smokers and for all smokers at the first examination. None of the relative risks is significantly different from 1 . The largest decrease in risk is somewhat unexpectedly seen for ischaemic heart disease.

In all smokers, the maximum decrease was 80 cigarettes, the maximum percentage decrease being $90 \%$. The maximum increase was 62 cigarettes and the maximum relative increase was 10-fold.

\section{DISCUSSION}

\section{Principal findings}

In heavy smoking men and women who have reduced their daily cigarette consumption by $>50 \%$, mortality of all causes combined is not reduced compared with mortality in those who continued as heavy smokers or those who did not reduce their consumption by as much as $50 \%$. Also for the causespecific mortality presented, we found no statistical difference between reducers and sustained heavy smokers.

It would be interesting to compare the results from the study of the three Norwegian counties with those presented from the Copenhagen Centre for Prospective Population Studies ${ }^{134}$ (table 8 ). Both studies are based on large populations that have been observed for long periods; both present relative risks for reducers with continuous heavy smokers as reference; and in both studies the relative risks have been adjusted for a series of confounding variables, which are partly the same for the two populations. For the reducers, the consumption decrease is about the same in the two countries.

The results are remarkably similar to each other. For mortality of all causes, and for ischaemic heart disease, cardiovascular disease and smoking-related cancer, there is no significant decrease in risk in reducers compared with sustained heavy smokers. The risk for lung cancer in reducers may differ slightly from this overall picture. For the Copenhagen population, the relative risk in reducers decreased by $27 \%$, with a confidence interval not covering zero effect. For the Norwegian population, the corresponding decrease in risk was 34\%, but this decline did not reach statistical significance. Moreover, for the Norwegian population, the analyses based on degree of consumption change showed that the reduction in cigarette consumption had only a modest and nonsignificant effect on mortality in all cause groups (table 7).

Certainly, the question remains as to whether the lower cigarette consumption at the second examination is due to under-reporting. Also, to what degree compensatory smoking (deeper inhalation and shorter butts) occurs in the reducers is yet unknown. Godtfredsen et $a l^{1-4}$ have discussed this question thoroughly. For our part, we find that the mean serum thiocyanate level is slightly higher in reducers than in the moderate smokers, although their mean cigarette consumption is slightly lower. This should point to the direction of some under-reporting in the reducers. We emphasise, however, that, compared with the heavy smokers, the reducers have a lower level of serum thiocyanate, although their all-cause mortality is exactly the same as that in the heavy smokers. This indicates that a substantial proportion of their reduction in consumption has been real, although its health consequences are largely unchanged.

One important point that we cannot fully tackle is the extent changes in smoking habits have taken place during the follow-up period. For the subgroup that underwent three examinations, however, it was possible to take into consideration the smoking status of the reducers 5 or 10 years later (table 6). There was no mortality reduction among those who remained as reducers compared with those who remained as heavy smokers. Those who had changed from reducers to quitters had, on the other hand, 50\% lower mortality than the sustained heavy smokers.

The sustained reducers had a mean daily cigarette consumption that was almost the same at the second and third examinations - that is, they had maintained their lower level of consumption between 5 and 10 years (in one county for at least 13 years). It is reasonable that their reduced daily consumption then had stabilised and had lasted for the remaining observation period. Some uncertainty still remains 
on this point, however, and it would have strengthened the study to elucidate this question further by a new screening later in the observation period.

The consumption increase in most of the subgroup that underwent three examinations may explain the observation made in fig 1 , that during the first 15 years male reducers have slightly lower total mortality than heavy smokers, and that they then catch up with the heavy smokers.

It should be added that background characteristics such as serum lipids, blood pressure, physical activity and body mass index $\left(\mathrm{kg} / \mathrm{m}^{2}\right)$ did not differ significantly between reducers and sustained heavy smokers. A change in cigarette consumption does not go together with a change in lifestyle factors beneficial to health.

A higher prevalence was seen, however, of disability pension and sick leave among the reducers. This could indicate that for some reducers, their lower cigarette consumption accompany a consequence of some disorder. To clarify this question, we conducted separate analyses excluding people who reported disability or sick leave (data not shown). This exercise, however, gave essentially the same risk estimates as those in table 4 .

Female reducers have clearly higher death rates than female heavy smokers, both from any cause and from smoking-related cancer. We have no explanation for this phenomenon, beyond the fact that this could be ascribed to chance.

\section{Strengths and weaknesses of the study}

The strength of the study is that it includes $>51000$ people who were examined according to standardised procedures and observed for a mean of more than two decades. The number of person-years is 566670 for men and 517977 for women. We have also information on a series of relevant confounding variables and of a biochemical marker in one of the counties. Furthermore, the follow-up is complete.

Although we have results from a third examination for $57 \%$ of the reducers, it would have strengthened the study if we could have made an even better assessment as to what extent some of our findings are due to changes in smoking habits later during the follow-up period.

\section{Possible implications for policymakers}

In health education and patient counselling, it is widespread to offer smokers a last resort: "If you are unable to quit, cut down".

Undoubtedly, reduction in consumption may have a place as a temporary measure in systematic smoking cessation. Nevertheless, the results of this study, and those of the Copenhagen Study, make it imperative to reassess this recommendation as a permanent solution, and raise the question whether it offers people false expectations.

The study proves quite clearly the only safe way out of the risk caused by smoking: people who quit smoking have achieved a risk level that is remarkably lower than in those who continued to smoke.

\section{CONCLUSION}

In both sexes, a reduction in cigarette consumption by $>50 \%$ was not associated with a markedly lower risk of all-cause mortality and, specifically, of dying from cardiovascular disease or smoking-related cancer. Accordingly, a reduction in consumption does not seem to bring about harm reduction.

\section{Authors' affiliations}

A Tverdal, Norwegian Institute of Public Health, Oslo, Norway K Bjartveit, National Health Screening Service, Oslo, Norway

\section{What this paper adds}

- Only one large prospective study from Copenhagen, Denmark, has so far explored the long-term effects of unassisted reduced smoking.

- The long-term effects of a substantial reduction in smoking did not show any benefits in comparison with persistent heavy smoking, with respect to all-cause mortality and premature deaths from cardiovascular disease, smoking-related cancer and respiratory disease.

- No notable reduction was found in risk of hospital admission for chronic obstructive pulmonary disease, and in incidence of fatal and non-fatal myocardial infarction. Incidence of lung cancer was reduced by about $25 \%$.

- This study, which includes over 51000 people who were examined twice at an interval of 3-5 years and observed over a mean of more than two decades, confirms in principle the results from the Copenhagen study.

- Compared with sustained heavy smokers, people with reduced cigarette consumption showed no reduced risk of all-cause mortality, or of premature deaths from ischaemic heart disease, cardiovascular disease and smoking-related cancer. There was a modest but insignificant reduction in risk of death from lung cancer.

- This study gives more detailed risk assessment by degree of change in daily cigarette consumption and gives results from a mortality follow-up of people who underwent a third examination some years after the second one, supporting the findings.

Competing interests: KB was involved in national and international tobacco control.

Contributors: $\mathrm{KB}$ and $\mathrm{AT}$ participated in designing the cardiovascular disease study in Norwegian counties. KB was responsible for the administration of the screening part. AT carried out the data extract and analyses. KB and AT drafted the paper.

\section{REFERENCES}

1 Godifredsen NS, Holst C, Prescott E, et al. Smoking reduction, smoking cessation, and mortality: a 16-year follow-up of 19,732 men and women from the Copenhagen Centre for Prospective Population Studies. Am J Epidemiol 2002;156:994-1001.

2 Godffredsen NS, Vestbo J, Osler M, et al. Risk of hospital admission for COPD following smoking cessation and reduction: a Danish population study. Thorax 2002;57:967-72.

3 Godffredsen NS, Osler M, Vestbo J, et al. Smoking reduction, smoking cessation, and incidence of fatal and non-fatal myocardial infarction in Denmark 1976-1998: a pooled cohort study. J Epidemiol Community Health 2003:57:412-16.

4 Godffredsen NS, Prescott E, Osler M. Effect of smoking reduction on lung cancer risk. JAMA 2005;294:1505-10.

5 Bjartveit K, Foss OP, Gjervig T, et al. The cardiovascular disease study in Norwegian counties. Background and organization. Acta Med Scand, 1979;(Suppl 634):1-70.

6 Bjartveit K, Foss OP, Gjervig T. The cardiovascular disease study in Norwegian counties. Results from first screening. Acta Med Scand, 1983;(Suppl 675):1-184.

7 Tverdal A, Thelle D, Stensvold I, et al. Mortality in relation to smoking history: 13 years' follow-up of 68,000 Norwegian men and women 35-49 years. $J$ Clin Epidemiol 1993;46:475-87.

8 Biartveit $K$, Tverdal A. Health consequences of smoking 1-4 cigarettes per day. Tob Control 2005;14:315-20.

9 Bjartveit K, ed. Håndbok for hjerte-karundersøkelsen. Oslo: Statens Skjermbildefotografering, 1980. 
10 Bjartveit K, ed. Håndbok for hierte-karundersøkelsen. Oslo: Statens Skjermbildefotografering, 1985.

11 Bjartveit K, Wøien G. Cardiovascular disease risk factors in Norway. Results from surveys in 18 counties. Oslo: Statens Helseundersøkelser (National Health Screening Service), 1997.

12 National Health Screening Service, Health Services of Finnmark, Sogn og Fiordane, and Oppland counties, Ullevål Hospital, Central Laboratory, Oslo. The cardiovascular disease study in Norwegian counties. Results from second screening. Oslo: National Health Screening Service, 1988.

13 Westlund K, Søgaard AJ. Helse, livsstil og levekår I Finnmark. Finnmark III, ISM skriftserie nr 28. Tromsø: Institute of Social Medicine, 1993.
14 Stensvold I. Coffee and health. Is coffee consumption a risk factor for cardiovascular disease or cancer?. Oslo: National Health Screening Service, 1996.

15 Foss OP, Lund-Larsen PG. Serum thiocyanate and smoking: interpretation of serum thiocyanate levels observed in a large health study. Scand J Clin Lab Invest 1986;46:245-51.

16 International Agency for Research on Cancer. Tobacco smoke and involuntary smoking, IARC Monographs on the Evaluation of Carcinogenic Risks to Humans. Vol 83. Lyon: International Agency for Research on Cancer, 2004.

17 Doll R, Peto R, Boreham J, et al. Mortality from cancer in relation to smoking: 50 years observation on British doctors. Br J Cancer 2005;92:426-9. 